\title{
Antibiotics for Post-Tonsillectomy Morbidity: Comparative Analysis of a Single Institutional Experience
}

\author{
Qais Aljfout ${ }^{\mathrm{a}, \mathrm{b}}$, Amjad Alississ $^{\mathrm{a}}$, Hesham Rashdan ${ }^{\mathrm{a}}$, Abdullah Maita ${ }^{\mathrm{a}}$, Mohammad Saraireh ${ }^{\mathrm{a}}$
}

\begin{abstract}
Background: We have conducted this study to evaluate the effect of antibiotics, whether oral or intravenous, compared to no antibiotic protocol on post-tonsillectomy morbidity.

Methods: A total of 270 patients aged 3 - 12 years were included in the study. Patients were assigned into three groups randomly; each group consisted of 90 patients. In the first group (group A), patients were given intravenous injections of ceftriaxone $50 \mathrm{mg} / \mathrm{kg} / 24$ hours in divided doses, the second group (group B) received oral co-amoxiclav (dose according to weight) for 5 days post-operatively, and in the third group, patients were not given antibiotics. Patients were evaluated for the incidence of any bleeding, number of days before resuming normal diet, incidence of nausea and vomiting, incidence of abdominal pain, frequency of analgesic use in the first week, and pain.

Results: Our study groups were comparable in age, gender, and weight. There were no statistically significant differences between our study groups with regard to the incidence of post-tonsillectomy bleeding, time relapsed to resume normal diet, and pain score scale. Incidence of nausea, vomiting, and abdominal pain was more in the oral antibiotic group, and it was statistically significant.
\end{abstract}

Conclusion: We do not recommend the routine use of antibiotics in post-tonsillectomy period in pediatric age group and oral antibiotics prove to have worse outcome with regard to the incidence of nausea, vomiting, and abdominal pain, and these recommendations need to be evaluated by multicenter evaluation.

Keywords: Bleeding; Ceftriaxone; Co-amoxiclav; Fever; Intravenous; Morbidity; Oral; Tonsillectomy

\section{Introduction}

Although tonsillectomy with or without adenoidectomy is one

Manuscript accepted for publication March 09, 2016

aOtorhinolaryngology, Head \& Neck Surgery Department, Royal Medical Services, Amman, Jordan

${ }^{b}$ Corresponding Author: Qais Aljfout, Otorhinolaryngology, Head \& Neck Surgery Department, Royal Medical Services, PO Box 1643 Tareq, Amman 11947, Jordan. Email: qaisj@yahoo.com

doi: http://dx.doi.org/10.14740/jocmr2523w of the most commonly performed surgical procedures worldwide, there are controversies in regard to best management for the significant post-tonsillectomy morbidity. Symptoms include odynophagia, dysphagia, decreased oral intake, otalgia, halitosis, and fever [1]. Since the first week after surgery can be extremely difficult for both child and parents, the hunt for reduction of the morbidity had led to search for best surgical technique, best regimes for pain killers' usage, whether to use steroids or not, antibiotics uses and choices, and even the use of natural products like honey [2-4]. After tonsillectomy, oral bacterial flora colonizes the open tonsillar surgical bed and this might lead to severe localized inflammatory reaction with subsequent pain exacerbation [2]; therefore, it is reasonable to assume that reduction of bacterial population at the open surgical wound may decrease local inflammation, promote healing process, and accelerate recovery [5]. Although Streptococcus pyogenes was once the pathogen responsible for $90 \%$ of cases of chronic tonsillitis, in the last decade, there has been increasing evidence that hemophilus influenza and Staphylococcus aureus may now play a prominent role. Both of these are B-lactamase producers and are characterized by multi-resistance to antibiotics [6]. Amoxicillin and clavulanic acid (co-amoxiclav) is a B-lactamase stable antibiotic and has a broad antimicrobial spectrum that includes oropharyngeal anaerobes, Gram-positive cocci, and most Gram-negative bacilli. It is highly active against the common pathogens in chronic recurrent tonsillitis [3]. Ceftriaxone is a parental expanded-spectrum cephalosporin with pharmacological characteristics $[7,8]$ and microbial activity against oropharyngeal microbes and particularly adapted to the treatment of acute otitis media unresponsive to previous therapy $[9,10]$. Routine antibiotic administration is not recommended by American Academy of Otolaryngology-Head and Neck Surgery Foundation guidelines for pediatric tonsillectomy [11]. In our practice, all of our patients are given oral antibiotics after tonsillectomy and we have conducted this study to evaluate and compare the effect of antibiotics given orally or intravenously with no antibiotic protocol on post-tonsillectomy morbidity in children.

\section{Methods}

This was a controlled double-blinded study. The study was conducted between September 2014 and December 2015. Approval of our institution ethical committee was granted and informed consents were obtained for all patients after explanation of our study. Two hundred seventy patients aged $3-12$ 
Table 1. Demographic Data of the Study Groups

\begin{tabular}{lllll} 
Parameter & Group A $(\mathbf{n}=\mathbf{9 0})$ & Group B $(\mathbf{n}=\mathbf{9 0})$ & Group C $(\mathbf{n}=\mathbf{9 0})$ & P value \\
\hline Age $($ mean \pm SD) $($ years $)$ & $6.2 \pm 2.3$ & $6.3 \pm 2.1$ & $6.1 \pm 2.3$ & $>0.05$ \\
Weight $($ mean \pm SD) $(\mathrm{kg})$ & $19.6 \pm 5.9$ & $20.2 \pm 5.7$ & $19.9 \pm 6.1$ & $>0.05$ \\
Sex $(\mathrm{M} / \mathrm{F})$ & $51: 39$ & $48: 42$ & $43: 47$ & $>0.05$ \\
\hline
\end{tabular}

years who were scheduled for elective tonsillectomy with or without adenoidectomy were included in the study, and all of them have ASA physical status I or II. Exclusion criteria were hypersensitivity to penicillin or ceftriaxone, signs of pharyngeal infection, and use of antibiotics 2 weeks before surgery. Paracetamol $15 \mathrm{mg} / \mathrm{kg}$ suppositories were given as premedication. Surgeries were performed under general endotracheal tube anesthesia with the same anesthetic technique using propofol $1.5 \mathrm{mg} / \mathrm{kg}$, fentanyl $1.0 \mu \mathrm{g} / \mathrm{kg}$, atracurium $0.5 \mathrm{mg} /$ $\mathrm{kg}$, midazolam $0.05 \mathrm{mg} / \mathrm{kg}$, and maintenance on mixture of oxygen air 1:1 with isoflurane $1 \%$; at the end of the surgery, patients were given neostigmine $50 \mu \mathrm{g} / \mathrm{kg}$ and atropine $20 \mu \mathrm{g} /$ $\mathrm{kg}$. Tonsillectomies were performed by using blunt surgical dissection technique in all cases and homeostasis was secured using bipolar diathermy electrocautery.

Patients were allocated into three groups by stratified randomization, with each consisting of 90 patients. In the first group (group A), patients were given intravenous (IV) injections of ceftriaxone $50 \mathrm{mg} / \mathrm{kg} / 24 \mathrm{~h}$ in two divided doses with a total of three doses. In the second group (group B), patients received co-amoxiclav (dose according to weight) for 5 days post-operatively, and in the third group (group C), the patients were not given any kind of antibiotics.

All patients were discharged home on the following day and parents were advised to bring their child to hospital if he/ she had any bleeding or fever. All patients were seen after 1 , 2 , and 4 weeks after surgery and clinical data abstract form was designed to collect our study data which include number of days before resuming normal diet, incidence of nausea and vomiting, incidence of abdominal pain, frequency of analgesic use in the first week, history of post-tonsillectomy bleeding, and pain using visual analogue pain score (0: little or no pain, 10: severe unbearable pain) which was utilized in an effort to objectively analyze the degree of pain by asking the patient or parents to mark along an unmarked $10 \mathrm{~cm}$ line where they felt their pain to be in the first week after surgery.

SPSS for Windows was used for statistical analysis, using $t$-test and Chi-squared tests when appropriate. All data were expressed as mean \pm standard deviation (SD). A value of $\mathrm{P}<$ 0.05 was considered statistically significant.

\section{Results}

Our study groups were comparable for age, gender, and weight $(\mathrm{P}>0.05)$. Group A was composed of $51(57 \%)$ male patients and $39(43 \%)$ female patients, with the mean age of $6.2 \pm 2.3$ years. Group B was composed of $48(53 \%)$ male patients and $42(47 \%)$ female patients, with the mean age of $6.3 \pm 2.1$ years, and group $\mathrm{C}$ was composed of 43 males $(48 \%)$ and 47 females $(52 \%)$, with the mean age of $6.1 \pm 2.3$ years (Table 1$)$.

All patients had uneventful $24 \mathrm{~h}$ post-operative period, and all were discharged on first day post-operatively with analgesics. At 1, 2, and 4 weeks post-operatively, patients were evaluated at outpatient clinic and there were no statistical differences between the two groups in regard to the time of resuming normal diet intake, incidence of fever, and pain scale, which was done at week 1 . Six patients of group A had history of bleeding, four of them had history of spitting blood once, and they did not seek medical care. Seven patients of group B had history of bleeding and only three of them had sought medical care. Seven patients of group C had history of bleeding, of whom four had sought medical treatment. None of those patients needed blood transfusion. But all of them were managed by third generation IV antibiotics, IV fluid support, and observation for $48 \mathrm{~h}$. In five patients, one from group A and two from each of the other two groups, the bleeding was controlled in the operating room and there was no statistically significant difference among the three groups. The incidence of nausea, vomiting, and abdominal pain was higher in group $\mathrm{B}$ and the differences were statistically significant. The incidence of fever was slightly higher in group $\mathrm{C}$, and all of them were given oral antibiotics (Table 2). None of our patients reported side effect of the medications used.

Table 2. Analysis Data of the Study Groups

\begin{tabular}{lllllll}
\hline Event & Group A & Group B & Group C & P value (A and B) & P value (A and C) & P value (B and C) \\
\hline Days before resuming normal diet (mean \pm SD) & $3.7 \pm 1.4$ & $3.5 \pm 1.8$ & $3.7 \pm 1.6$ & 0.407 & 1.00 & 0.431 \\
Fever & 6 & 7 & 9 & 0.773 & 0.560 & 0.793 \\
Nausea and vomiting & 9 & 22 & 11 & 0.018 & 0.31 & 0.054 \\
Abdominal pain & 7 & 19 & 10 & 0.019 & 0.105 & 0.578 \\
Analgesics use/day in first week (mean \pm SD) & $3.4 \pm 1.1$ & $3.7 \pm 1.3$ & $3.6 \pm 1.1$ & 0.096 & 0.224 & 0.504 \\
Pain score for the first week (mean \pm SD) & $6.2 \pm 1.8$ & $5.9 \pm 2.1$ & $6.1 \pm 1.9$ & 0.305 & 0.717 & 0.773 \\
Bleeding & 7 & 6 & 7 & 0.773 & 1.0 & \\
\hline
\end{tabular}




\section{Discussion}

Although tonsillectomy is a short procedure, it has a concerning post-operative morbidity for all, surgeons, patients, and parents. It is well known that the first week after surgery is the worst. A lot of treatment options have been used and none of them prove to be consistently successful [2].

The bacterial colonization of the open tonsillar bed after tonsillectomy may lead to an inflammatory response which will have negative effect on the post-operative morbidity [12, 13] and this inflammatory response leads to the release of inflammatory mediators which increase the oropharyngeal muscles spam and increase the post-operative pain and this factor combined with the effect of tissue ischemia due to muscle injury regardless of the technique used in dissection will lead to worse pain cycle [14]. In order to minimize tissue trauma during surgery, a lot of studies had evaluated and compared dissection techniques used, whether simple dissection or powered dissection or cold dissection or hot electric dissection [3] and this is the rationale behind our study, which is to evaluate the best treatment options which include no antibiotic option to reduce inflammatory response due to bacterial colonization in order to reduce post-operative pain and hence morbidity and enhance recovery. The bacterial colonization theory had been evaluated by many researchers and some of them found that groups given antibiotics post-operatively had better outcome in terms of resumption of regular diet, less halitosis, and return to normal daily activities [5, 13, 14]. Even the incidence of post-tonsillectomy hemorrhage was reduced [15]. A Cochrane database systematic review in 2012 advocated the conclusion against the routine use of antibiotics to patients undergoing tonsillectomy [16]; we have noticed that all Cochrane reviews were done by the same group! Recent studies raised two issues against the American guidelines. The first one is that a significant percentage of surgeons in the United States continued to use antibiotics routinely despite the guidelines [17]. The second issue is a small but considered significant increase in surgery for post-tonsillectomy bleeding following the publication of the guidelines [18]. The incidence of fever is the only concern in protocols that do not recommend the use of antibiotics, and in such incidences, they do give antibiotic [11].

In this study, we had challenged our practice in routine antibiotics use in tonsillectomy patients, and we had thought that compliance to oral antibiotics in pediatric age groups is an important issue as well as the gastric upset caused by the antibiotic itself or by the exaggerated response of the child himself, and the daily intake of oral antibiotics might increase the sense of being sick in the post-operative period which is needed to be minimized in order to resume normal life. And we had found that two doses of IV antibiotics and even no antibiotic protocol are as safe and effective as prolonged oral course and this is comparable to findings of other researchers who had found that the use of single-dose preoperative IV cephalothin was as efficient as the use of oral amoxicillin/clavulanate for 7 days in reducing morbidity in children undergoing tonsillectomy and offers safe antimicrobial prophylaxis. And they advise that the routine use of oral antibiotics should be avoided [19]. Also we had noticed that the incidence of nausea, vomit- ing, and abdominal pain was more in the oral antibiotic group. On the other hand, some studies found that there was no difference between groups who received antibiotics and control group with regard to post-tonsillectomy morbidity [20] and one study had reported worse outcome in the antibiotic group than the control group [21].

\section{Conclusion}

We do not recommend the routine use of antibiotics in posttonsillectomy period in pediatric age group and oral antibiotics prove to have worse outcome with regard to the incidence of nausea, vomiting, and abdominal pain in comparison to IV antibiotics or no antibiotic protocol. Fever is the only indication to give oral antibiotics in post-tonsillectomy period, and these recommendations need to be evaluated by multicenter evaluation.

\section{Conflict of Interest}

None.

\section{Funding}

None.

\section{References}

1. Schmidt R, Herzog A, Cook S, O'Reilly R, Deutsch E, Reilly J. Complications of tonsillectomy: a comparison of techniques. Arch Otolaryngol Head Neck Surg. 2007;133(9):925-928.

2. Piltcher OB, Scarton FB. Antibiotic use in tonsillectomies: therapeutic or prophylactic? Required or excessive? Braz J Otorhinolaryngol. 2005;71(5):686-690.

3. Colreavy MP, Nanan D, Benamer M, Donnelly M, Blaney AW, O'Dwyer TP, Cafferkey M. Antibiotic prophylaxis post-tonsillectomy: is it of benefit? Int J Pediatr Otorhinolaryngol. 1999;50(1):15-22.

4. Amani S, Kheiri S, Ahmadi A. Honey versus diphenhydramine for post-tonsillectomy pain relief in pediatric cases: a randomized clinical trial. J Clin Diagn Res. 2015;9(3):SC01-04.

5. Page CP, Bohnen JM, Fletcher JR, McManus AT, Solomkin JS, Wittmann DH. Antimicrobial prophylaxis for surgical wounds. Guidelines for clinical care. Arch Surg. 1993;128(1):79-88.

6. Mevio E, Perano D, Pagani L, Zanella C, Giacobone E, Cardillo A. The role of tissue colonization and bacterial resistance in recurrent tonsillitis. Acta Otolaryngol Suppl. 1996;523:133-137.

7. Craig WA, Andes D. Pharmacokinetics and pharmacodynamics of antibiotics in otitis media. Pediatr Infect Dis J. $1996 ; 15(3): 255-259$. 
8. Gudnason T, Gudbrandsson F, Barsanti F, Kristinsson KG. Penetration of ceftriaxone into the middle ear fluid of children. Pediatr Infect Dis J. 1998;17(3):258-260.

9. Bingen E, Bourrillon A. [Resistant pneumococci in pediatrics: therapeutic implications]. Presse Med. 1995;24(2):137-142.

10. Dixieme Conference de Consensus en The rapeutique Anti-Infectieuse. Les infections ORL. Med Mal Infect. 1996;26(Suppl):333-340.

11. Baugh RF, Archer SM, Mitchell RB, Rosenfeld RM, Amin R, Burns JJ, Darrow DH, et al. Clinical practice guideline: tonsillectomy in children. Otolaryngol Head Neck Surg. 2011;144(1 Suppl):S1-30.

12. Mann EA, Blair EA, Levy AJ, Chang A. Effect of topical antibiotic therapy on recovery after tonsillectomy in adults. Otolaryngol Head Neck Surg. 1999;121(3):277282.

13. Grandis JR, Johnson JT, Vickers RM, Yu VL, Wagener MM, Wagner RL, Kachman KA. The efficacy of perioperative antibiotic therapy on recovery following tonsillectomy in adults: randomized double-blind placebo-controlled trial. Otolaryngol Head Neck Surg. 1992;106(2):137-142.

14. Orzac E. Medical care of the child before and after adenoidectomy and tonsillectomy. New York: J Med. $1956 ; 886$.
15. Gaffney RJ, Walsh MA, McShane DP, Cafferkey MT. Post-tonsillectomy bacteraemia. Clin Otolaryngol Allied Sci. 1992;17(3):208-210.

16. Gil-Ascencio M, Castillo-Gomez CJ, Palacios-Saucedo Gdel C, Valle-de la OA. Antibiotic prophylaxis in tonsillectomy and its relationship with postoperative morbidity. Acta Otorrinolaringol Esp. 2013;64(4):273-278.

17. Dhiwakar M, Clement WA, Supriya M, McKerrow W. Antibiotics to reduce post-tonsillectomy morbidity. Cochrane Database Syst Rev. 2012;12:CD005607.

18. Padia R, Olsen G, Henrichsen J, Bullock G, Gale C, Stoddard G, Ott M, et al. Hospital and Surgeon Adherence to Pediatric Tonsillectomy Guidelines Regarding Perioperative Dexamethasone and Antibiotic Administration. Otolaryngol Head Neck Surg. 2015;153(2):275-280.

19. Milder EA, Rizzi MD, Morales KH, Ross RK, Lautenbach E, Gerber JS. Impact of a new practice guideline on antibiotic use with pediatric tonsillectomy. JAMA Otolaryngol Head Neck Surg. 2015;141(5):410-416.

20. Guerra MM, Garcia E, Pilan RR, Rapoport PB, Campanholo CB, Martinelli EO. Antibiotic use in post-adenotonsillectomy morbidity: a randomized prospective study. Braz J Otorhinolaryngol. 2008;74(3):337-341.

21. Pitrez FA, Pioner SR, Kiss G. In: Pitrez FA, Pioner SR et al. Pre e pos-operatorio em cirurgia geral e especializada, segunda edicao. Porto Alegre: ArtMed; 2003. p.117-129. 